\title{
Clinical proteomics of enervated neurons
}

\author{
Mohor Biplab Sengupta ${ }^{\dagger}$, Arunabha Chakrabarti ${ }^{\dagger}$, Suparna Saha and Debashis Mukhopadhyay*
}

\begin{abstract}
The dynamic field of neurosciences entails ever increasing search for molecular mechanisms of disease states, especially in the domain of neurodegenerative disorders. The previous century heralded the techniques in proteomics when indexing of the human proteomes relating to various disease conditions became important. Early stage research in certain diseases or pathological conditions requires a more holistic approach of first discovering the proteins of interest for the condition. Despite its limitations, proteomics is one of the most powerful techniques available to us today to dissect the molecular scenario in a particular disease situation. In this review we will discuss about the current clinical research in neurodegenerative disorders that employ proteomics techniques. We will specifically focus on our understanding of Alzheimer's disease, traumatic spinal cord injury and neuromyelitis optica. Discussions will include ongoing worldwide research in these areas, research in India and specifically our laboratory in these domains of neurodegenerative conditions.
\end{abstract}

Keywords: Neurodegeneration, Proteomics, Alzheimer's disease, Spinal cord injury, Neuromyelitis optica

\section{Background}

The most polarized cells of the human body, neurons, are a specialized type with respect to their functional properties. Development and function of neurons are closely linked to the bidirectional transport of molecules from the synaptic end to the cell body. This very synaptic signal, which when disrupted, causes the dysfunction of neuronal activities. Disruption in axonal transport is the cause of several neurodegenerative disorders $[1,2]$. In the realm of peripheral neuron injury, retrograde transport of molecules from the site of injury to the cell body of a peripheral neuron primes the latter to regenerate $[3,4]$. This phenomenon is absent in the central nervous system (CNS), with the consequence of regeneration after CNS injury being elusive even with years of research. Partly because of the large distance separating the axon end from the cell body, many molecular events after a trauma or a neuronal disease occur without any transcriptional manifestations [5]. Local proteolysis, protein synthesis

\footnotetext{
*Correspondence: debashis.mukhopadhyay@saha.ac.in

${ }^{\dagger}$ Mohor Biplab Sengupta and Arunabha Chakrabarti contributed equally to this work

Biophysics and Structural Genomics Division, Saha Institute of Nuclear

Physics, 1/AF Bidhannagar, Kolkata, West Bengal 700064, India
}

and post translational modifications are the key to understanding axonal events after an assault or a disorder of the neuron [5]. Proteomics approaches have therefore come to the limelight in recent times. In this review, we will discuss the contributions of our group from this perspective and also the prospective ideas in three neurological degenerative situations, namely Alzheimer's disease (AD), traumatic spinal cord injury (SCI) and neuromyelitis optica (NMO) and explore the advances in understanding these pathological processes using proteomics approaches.

\section{Ethics statement}

The data provided in the review was collected by a joint collaborative study of SINP and NRSMC\&H, Kolkata, India, after it was approved by Institutional Ethical Committees. An informed written consent was obtained from the subjects as per Helsinki Declaration, 2013.

\section{Clinical proteomics in AD}

During the past few years Mass spectrometry (MS) based proteomics tools have been used extensively to study ADrelated proteome changes in blood (plasma and serum), cerebrospinal fluid (CSF) samples and in postmortem 
brain tissues [6]. Since the pathological processes of AD start decades before the first symptoms appear, the objective of all AD proteomics studies have been to identify precisely the early diagnostic and prognostic biomarkers. Here we review reports that have used diverse samples including blood, CSF, brain tissues and also discuss different aspects of proteome status like posttranslational modifications (PTMs), redox proteomics and interaction proteomics.

Blood and CSF proteomics studies are being done for more than a decade to identify AD-related biomarkers, of which the most widely researched one is the peptide Amyloid $\beta(A \beta)$. Utility of $A \beta$ as a predictor of dementia and $A D$ is well established and it is evident that lower $A \beta_{42}: A \beta_{40}$ ratios are mainly associated with the disease [7]. In 2007, a plasma proteomic study in AD patients identified six potential plasma biomarkers using 2D-GE and LC/MS/MS [8]. Some of them, for example $\alpha-1$ antitrypsin, could be validated for its higher expression level in plasma of $\mathrm{AD}$ patients using ELISA. Apolipoprotein $J$ was found to be in lower abundance in plasma of $A D$ patients in an isoform-specific manner. This observation could only be achieved through 2-DE but could not be validated through biochemical methods like ELISA or Western blot. Recently, a large scale replication study was conducted for 94 proteins out of 163 potential candidate biomarkers found in 21 published blood proteomics studies. 9 were found to be associated with AD-related phenotypes [9]. It was concluded that there are replicable changes in proteomic expressions in blood of $\mathrm{AD}$ patients that can be identified by different studies with some consistency.

The rationale of studying plasma and CSF biomarkers for AD has been explicitly reviewed [10] and the diagnostic performance of the core CSF biomarkers, namely total tau, phosphorylated tau and $A \beta-42$ has been discussed. But studying these traditional biomarkers is not sufficient to identify preclinical AD. Study of differential proteome from whole tissue/body fluids in the disease model compared to that of the normal control is of immense importance in order to identify key, novel protein candidates for the disease. Recently, combination of $A \beta$, tau and p-tau along with several novel biomarkers in CSF have been used extensively for diagnostic confirmation of $\mathrm{AD}$ [11]. It is realized that co-development of biomarkers for early diagnosis and novel therapeutic approaches, together could be the way to go.

A recent review has extensively discussed the features of neurodegeneration proteomics and its importance in relation to PTM [12]. Evaluation of functional alterations in proteins due to PTMs can be achieved by means of a battery of proteomic tools. For the elucidation of pathogenic mechanisms, study of PTMs in AD is of immense importance and would become the future of proteomics research to understand the disease process. Very recently, the CSF glycoproteome was studied as a fingerprint of the brain glycoproteome of AD patients [13] and it is concluded that CSF $\mathrm{N}$-glycome analysis may provide reliable biomarkers for early diagnosis of the disease. In many studies, proteins from CSF of AD patients are shown to have differential isoforms in terms of glycosylation [14], S-nitrosylation [15] and histone protein modifications [16] in different tissue sections of the AD brain. Recently quantitative phosphoproteomics studies in the frontal cortex [17] and hippocampi [18] of AD brains have deciphered the deregulation of biological pathways in $\mathrm{AD}$ due to alteration in the PTM status. A more recent study deals with changes in protein phosphorylation status in the inferior parietal lobule of subjects with different stages of the disease (AD, Mild Cognitive Impairment, MCI, Pre-Clinical Alzheimer's Disease, PCAD) and control brain [19]. Phosphorylation status of nineteen proteins is found to be different in these stages of the disease. These proteins are involved in energy metabolism, neuronal plasticity, signal transduction and oxidative stress response. The same group has studied and discussed the effects of $A \beta$-induced oxidative stress, its redox proteomics and its importance in disease pathology and progression [20, 21]. Also, selectively oxidized proteins namely, creatine kinase $\mathrm{BB}$, glutamine synthase, ubiquitin carboxy-terminal hydrolase L-1, alpha-enolase, triose phosphate isomerase and neuropolypeptide h3 in human samples were identified and can be studied in future to understand the AD pathogenesis better [22, 23]. Redox proteomics analysis has been conducted to identify specific carbonylated proteins (for example, alpha-enolase, glutamine synthetase, protein disulfide isomerase A3 etc.) in the hippocampus at the very early stage in $A D$ mouse model [24].

A recent study with micro dissected neurons from the temporal cortex of AD brain has identified more than 400 proteins using LC-MS analysis [25]. Several recent studies have dealt with targeted and localized quantitative proteomics in presynaptic and postsynaptic tissue samples in $\mathrm{AD}$ and have identified a large number of proteins relevant to the disease process [26-28]. All these studies aim at identifying novel candidates or imprints for early diagnosis of a neurodegenerative condition like AD.

\section{AD clinical proteomics in India: Interaction proteomics with focus on APP intracellular domain (AICD)}

There have not been many studies in the domain of Alzheimer's disease research employing proteomics approach. Although there are extensive reviews discussing employment of proteomics for biomarker discovery 
in neuropsychiatric disorders [29] and of the relation of $\mathrm{AD}$ and type-2 diabetes [30], only one clinical proteomics study with AD CSF samples has been conducted [31]. This study has found Apolipoprotein E, Apolipoprotein J, Hemopexin, Complement factor $\mathrm{b}$ and complement $\mathrm{C} 4 \mathrm{~b}$ to be differentially abundant in AD versus control CSF samples.

Our laboratory focuses on interaction proteomics of amyloid precursor protein (APP) intracellular domain (AICD). AICD generated by post $\gamma$-secretase cleavage of APP has been an important molecule of the AD pathway and has drawn the focus of many researchers [32-35]. In the dephosphorylated state, it acts as a transcriptional transactivator to regulate the expression of several genes including GSK3 $\beta$ [36]. Once phosphorylated, it interacts with a plethora of other cellular adaptors, heavily influencing the cellular machinery. In an attempt to identify the intracellular interacting partners of phosphorylated AICD, we found twenty novel AICD interacting partners from mouse neuroblastoma cells [37]. Molecular functions of several of these interactors, for example ApoA4, GAB2, HSPA8, vimentin etc., could be correlated to AD, revalidating that AICD and its interactions have implications towards $\mathrm{AD}$ pathophysiology. In a different study, we could identify AICD interacting proteins from CSF of $\mathrm{AD}$ patients and also compare the differential expressions of these interactors with respect to that of non-demented control patients [38]. Keeping the need for identifying the indirect candidates involved besides the direct ones for in-depth exploration of the molecular networks of the disease, we transfected AICD in mouse and human neuroblastoma cell lines and identified differential expressions of proteins belonging to diverse molecular pathways [39], for example, ER-stress (GRP78), structural remodeling (vimentin) and general stress (HSP90 $\beta$, HSPA8).

\section{Clinical proteomics in spinal cord injury}

Acute traumatic injury of the spinal cord resulting in partial or total deficits in sensory and/or motor functions is widely prevalent worldwide and leads to considerable decline in the quality of life [40]. Though relative annual incidences of SCI vary with the geographical region and the time period of the study [41], studies show that global average incidence is highest in Asia [40] with 43.8 persons per million people afflicted. Traffic accidents [42], fall from height [43] and violence [44] constitute some of the major reasons for SCI.

Autonomic dysfunctions that follow SCI set the major decline in the quality of life of afflicted persons. An injury above the $\mathrm{C} 3$ level in the vertebral column may lead to immediate cardiac arrest necessitating assisted respiration [45]. While the autonomic deregulations may last for a period of weeks after an injury, grossly the pathophysiology of SCI is divided into primary and secondary injuries. The initial trauma to the spinal cord is called primary injury and it is a prognostic indicator of SCI [46]. Following the primary injury, secondary injury sets in [47] and may last from months to years. This phase witnesses a plethora of degenerative phenotypes attributed to multitudes of molecular responses to injury [48].

Therefore, in spinal cord injury research, it is very important to get a clear picture of the molecular anatomy at the vicinity of the injury. On the other hand, for the peripheral nerve injuries, which comprise a greater subset of neuronal injuries, study of molecular parameters promoting axonal regeneration is of paramount importance [49]. Axon forms an important tissue to analyse changes following an injury. This is because of a temporal sequence of three events promoting neuron regeneration: discharge of axonal potentials induced by injury, interrupted normal supply of retrogradely transported targetderived factors, and retrograde injury signals travelling from the injury site back to the cell body, also called positive injury signals [50]. Here, the necessity of biomarker analysis is born. Especially, proteomics approaches are preferred to those of genomics in the domain of axonal regeneration and degeneration because changes in axons often occur without any transcriptional events in the cell body, following a pathological condition [5]. Moreover, a large number of PTMs to proteins accompany axonal degeneration and regeneration, which has been rightfully termed as a 'postgenomics' problem. A series of elegant work from the group of Perlson et al., beginning with proteomics approach, showed that vimentin is translated at the site of axonal injury [51], it is retrogradely transported from the site of injury to the cell body on dynein motor [52] and binds with ERK preventing its dephosphorylation [53].

\section{Clinical proteomics tools to discover molecular interplay post $\mathrm{SCl}$}

Application of proteomics in biomarker analysis in traumatic SCI has found inflammatory cytokines at elevated levels and documented the elevation of tau, S100beta, GFAP and MCP-1 in a severity dependent fashion [54]. Commonly deregulated proteins as fished out by proteomics studies, include plasma proteins, HSPs, glycolytic enzymes, antioxidants and proteins participating in DNA damage and repair, protein degradation, cell signaling and structural proteins $[55,56]$. Transgelin and protein S100-A11 were found to be biomarkers of bladder healing in the secondary injury phase of rats [57]. An early study with insoluble segments of injured rat spinal cord using 2-DE followed by MALDI-TOF/TOF found decreased abundance of pyruvate dehydrogenase beta, 
aconitase 2, fumarate hydratase 1, and ATP synthase subunit 6, which can lead to ATP depletion. On the other hand, antioxidant proteins such as catalase and PRDX-1 were decreased [58]. Implication of antioxidants were further shown with the aid of 2-DE where decreased abundance of catalase (CAT) and Mn-superoxide dismutase (Mn-SOD) were detected at the lesion centre 14 days post SCI in rats [59]. Additionally galectin-3, beta actin, actin regulatory protein (CAPG) and F-actin capping protein subunit beta (CAPZB) were found increased at similar time period post injury suggesting a decrease in antioxidant function and increase in growth inhibiting proteins post SCI. Treatment with acidic fibroblast growth factor (aFGF) down-regulated regenerationblocking secondary phase proteins like S100beta, GFAP and the keratin sulphate proteoglycan, lumican, as demonstrated using proteomic approaches in rat SCI model [60]. Tyrosine 3-monooxigenase/Tryptophan 5-monooxigenase activation protein (YWHAZ), a hub of several signal transduction pathways, glutathione peroxidise 3, involved in detoxifying hydrogen peroxide and S100a8, which is zinc and calcium binding protein involved in immune response regulation, were found to be biomarkers of severity in rats at $24 \mathrm{~h}$ post injury [61]. AfjehiSadat et al. showed higher abundance of 14-3-3 epsilon protein, dynein light chain 1 , and tubulin beta- 5 chain and decreased abundance of adenylyl cyclase associated protein 1, dihydropyrimidinase-related protein 2, F-actin capping protein subunit beta, glyceraldehyde-3-phosphate dehydrogenase, stress-induced phosphoprotein 1 and transthyretin in injured tissue of SCI in rats. Free oxygen radical attack on proteins in SCI was indicated by PTM analysis [62].

Limitations of identifying a larger number of proteins using conventional 2-DE methods prompted researchers to use multiplex array proteomics to analyse low abundance proteins from CSF available in small volumes. A cytokine profiling from CSF of cervical SCI rats at 12 days post injury revealed MMP- 8 to be an elevated biomarker [63]. Proteomics approaches have been employed to decipher the temporal changes of protein expression after SCI. This is particularly important because protein expression pattern is drastically disturbed following an injury and there is a prolonged persistence of irregularities in protein expression patterns thereafter. Zhu et al. found that $24 \mathrm{~h}$ post injury is the key time when the protein expression changes drastically in a rabbit SCI model [64].

Use of labeling with iTRAQ reagent coupled with proteomics approaches have derived significant results in the domain of SCI. LC-MS/MS with iTRAQ reagent labeling identified proteins involved in ubiquitination, endocytosis and exocytosis, energy metabolism, inflammatory response, oxidative stress, cytoskeletal disruption, and vascular damage as altered significantly at $24 \mathrm{~h}$ after SCI in rats [65]. Heat shock proteins were significantly differentially expressed in a rat model of SCI found in a study using iTRAQ and 2D LC-MS/MS [66] pointing to their potential role after SCI. 2-DE followed by nano ultra-high performance liquid chromatography-electrospray tandem mass spectrometry (NanoUPLC-ESIMS/MS) identified proteins associated with apoptosis, nerve signal transduction and metabolism to be differentially regulated in rat SCI followed by treatment with basic fibroblast growth factor long circulation liposome (bFGF + LCL) [67].

\section{Proteomics of $\mathbf{S C l}$ in India}

Currently, even though there are numerous studies being done on various, mostly rehabilitative [68], epidemiological [69], financial [70], clinical [71, 72] and surgical [73] aspects of SCI in India, use of proteomics approach to get into the molecular level has been done only in our laboratory.

We have been focusing on the molecular interplay occurring in the secondary phase of SCI, which essentially manifests as the various phenotypic dysfunctions associated with this stage. For this purpose we conducted a clinical sampling with 14 SCI patients at 1-8 days post injury and contrasted their cerebrospinal fluid (CSF) from complete and incomplete injury types. The injury severities were ascertained using the American Spinal Injury Association (ASIA) Impairment Scale (AIS) [74]. 2-DE followed by MALDI MS/MS was employed to identify CSF proteins from SCI patients and furthermore, 2D-DIGE was conducted to contrast the different AIS samples of CSF [56]. Forty-nine proteins were identified from CSF of SCI cases. Eight of them were differentially abundant $(\geq \pm 1.5$ fold) among AIS A (complete injury) and AIS C (incomplete injury) CSF samples. The status of the differentially abundant proteins among the AIS groups was further checked for CSF taken at 15-60 post injury from an additional 6 patients.

Application of bioinformatics tools to the identified proteins from SCI CSF yielded a protein-protein interaction network (PPIN) consisting of the identified proteins and their secondary interactors. From this network, interaction modules were created where protein members within a module interact more with one another than with proteins outside of the module. We adopted the Newman-Girvans modularization (NGM) algorithm [75-77]. Thus a modularised network was formed. The network was further enriched [78] to identify biological functions associated with the modules. This was done using GeneCodis3 [79]. 
Finally identifying the modules where the differentially abundant proteins were found, we zeroed in on the perturbed biological pathways post SCI at the secondary phase. The significantly perturbed pathways were mRNA metabolism, protein phosphorylation, iron transport, lipid and ATP catabolism, tRNA and rRNA transcription and DNA repair. We therefore identified some molecular pathways that lose their balance post SCI and we started off with identifying the entire proteome of SCI CSF and gradually narrowing down from there. The employment of proteomics tools was immensely useful in our case as we did not start with any particular protein or pathway in mind. This holistic approach with gradual focus on the important results is thus a preferred choice not only in the domain of biomarker discovery but also in a situation like ours, where a molecular dissection is being carried out.

\section{Neuromyelitis optica}

Neuromyelitis optica (NMO) or Devic's disease is an autoimmune inflammatory disease that affects the central nervous system, predominantly the optic nerves and spinal cord [80, 81]. Devic's disease, because of its resemblance with multiple sclerosis was initially speculated to be a variant of the latter. But with advances in clinical and immunological studies, the existence of NMO as a distinct disease has been established [82, 83]. The clinical features associated with the disease include optic neuritis and transverse myelitis [84]. The disease can be either monophasic or relapsing [84]. In 2006 after the discovery of anti AQP4-IgG [85] the initially proposed diagnostic criteria for NMO was revised. The seropositivity of NMO autoantibody together with optic neuritis and longitudinal extensive transverse myelitis was then considered as the defining parameter for NMO [86].

As compared to other neurodegenerative disorders the global distribution of NMO is rather limited [87]. Its prevalence among Caucasians is low where the abundance of multiple sclerosis is high [88, 89]. Higher incidence of NMO has been reported among south Asian countries like India, Korea and the Philippines [90]. Demographic studies reveal that women are more predisposed to the disease than men [91, 92]; this is true even for the paediatric cases [93]. The disease mainly afflicts young adults with ages ranging mostly under 18 years although there have been some reports of late onset too $[94,95]$. The administration of immunosuppressive drugs has been the major treatment for the disease [96].

\section{Advances in proteomic study of NMO}

The presence of serum antibody NMO-IgG among the patients [85] was initially considered to be highly specific for disease confirmation but later it was seen that all patients were not NMO-IgG seropositive. Evidently it became crucial to look for other biochemical markers of the disease. Proteomic analysis which has been extensively employed in biomarker discovery for similar diseases like multiple sclerosis [97] was extended thereafter for the detailed study of NMO. The major study of NMO proteomics has been conducted in CSF, blood and urine. The insight into different CNS diseases is provided by CSF proteomics $[98,99]$. CSF comparative proteomics with multiple sclerosis, $\mathrm{NMO}$ and normal patients by Jiang et al. led to identification of four proteins namely-Pre-Albumin (PA), Keratin1, transferrin and Keratin 9 [100]. PA had high expression levels among multiple sclerosis patients while Keratin 1 was significantly increased in NMO patients. Transferrin (Tf) is a crucial marker for blood-brain-barrier (BBB) damage [101] and its high levels in NMO are indicative of the damage caused to the blood-brain-barrier because of NMO pathogenesis. In a separate study by Bai et al., proteome analysis in the CSF of NMO patients in comparison to control group revealed the up regulation of Neurofilament, Haptoglobin, immunoglobulin kappa chain $\mathrm{C}$ region (IGKC) and immunoglobulin heavy chain gamma 3 (IGHG3) levels [102]. In the same group of patients there was downregulation in alpha-1 1 -glycoprotein (A1BG), fibrinogen gamma chain (FGG), apolipoprotein A-IV (ApoA-IV), apolipoprotein E (ApoE), transthyretin (TTR) and vitamin-D binding protein (DBP) levels. Among NMO patients the rise in IGKC and IGHG3 and the downregulation of ApoA-IV levels hints at the involvement of immunological mechanisms in disease progression. Neurofilament, a protein localised in the axon usually reflects the axonal health [103]. The expression of this protein in NMO poses it as a biomarker for the disease. In another serum proteomic study by Jiang et al., there was a two-fold elevation in the levels of haptoglobin in NMO patients in comparison to control as well as multiple sclerosis cases [104]. Nielson et al. revealed an increase in levels of immunoglobulins Ig-G3, Ig-K and Ig-L in the urine proteome of NMO subjects in comparison to healthy subjects [105]. The differential expression profiles that have been obtained using two dimensional (2D) gel electrophoresis in combination with mass spectrometry, in totality, projects several probable biomarkers that would guide in the diagnosis of NMO.

The futuristic approach of such proteomic profiling studies is to investigate the potential cellular players that are differentially expressed among the seropositive and seronegative groups of NMO patients. This would be extremely crucial both in terms of classification as well as treatment of these two different subgroups of NMO patients. 


\section{Conclusions}

The endeavor in our laboratory for the past 8 years has been centered on understanding mechanisms leading to nervous system trauma-be it a disease or an injury. Starting with Alzheimer's disease, additional requirement of biomarkers aside from the most basic CSF ones, tau, phosphorylated tau and $A \beta-42$, prompted proteomics based research in this domain. The search identified several plasma and CSF biomarkers for AD. Further on, research from our laboratory has highlighted the interaction proteome of AICD in a cell based and clinical model. The follow-up studies dealing with candidate biomarkers identified through proteomics which are functionally linked to important biochemical pathways, are very crucial for the advancement of understanding the disease pathophysiology.

Coming on to spinal cord injury, the bulk of biomarker discovery has always employed proteomics methods. Since the lack of primary neuron regeneration beyond the injury point remains evasive, there is tremendous ongoing research in this area. Proteomics research in past decades have highlighted the role of cytokines in trauma pathology as well as those of plasma proteins, HSPs, glycolytic enzymes, antioxidants and DNA damage and repair proteins, protein degradation, cell signaling and structural proteins. Research from our laboratory has highlighted several perturbed molecular pathways post SCI, which include protein phosphorylation, DNA repair, mRNA metabolism, iron transport tRNA and rRNA transcription and lipid and ATP catabolism.

Neuromyelitis optica is a relatively less studied pathological condition when compared to the previous two and we have just started working with clinical samples. Anti AQP4-IgG was discovered in 2006 as a biomarker for NMO. A curious feature of this disease is that in several cases it has been observed that patients with NMO were not seropositive for the NMO-IgG. This prompted us to look for reliable candidate biomarkers and although studies have been limited so far, proteomics approaches look promising in this particular upcoming area of neurological disorder.

While working with nervous system we believed that proteomics approaches favor the initial 'biomarker discovery' stage of a research paradigm of a disease. It is particularly useful in diseases of the neurological disorders or injury as CSF and plasma form the common target sources of protein profile detection in the initial and also subsequent stages of identification of pathology mechanisms. Figure 1 represents the research strategies adopted by the Mukhopadhyay laboratory to study the three neuro-pathological conditions, $\mathrm{AD}, \mathrm{SCI}$ and $\mathrm{NMO}$.

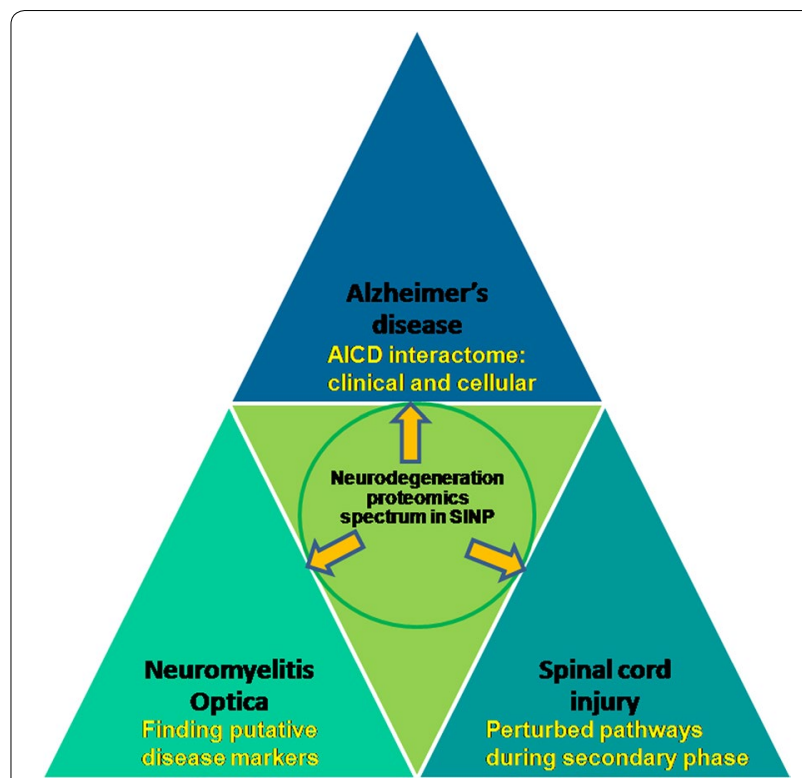

Fig. 1 A representative diagram of the paradigm adopted by our laboratory in neurodegeneration research. Starting with Alzheimer's disease, in proteomics domain, we found out the interacting partners of AICD in CSF and AICD-transfected human and mouse cell lines. Twenty novel AICD interactors were found in mouse neuroblastoma cells. The study was further followed up in human CSF, where differentially expressed AICD interactors were found out. Finally, differential expression of AICD interactors were studied in human and mouse neuroblastoma. Moving forward to spinal cord injury, we looked at differentially abundant proteins in the CSF of SCI patients with different severity grades of injury. An interaction network was created using the proteins found in the CSF of AIS grade A injury and modularization of the same revealed a number of perturbed pathways. Finding putative disease markers for the rather evasive successful marker hunting in neuromyelitis optica remains a future perspective

\section{Authors' contributions}

MBS participated in the investigation of perturbed pathways post traumatic $\mathrm{SCl}$ and drafted the manuscript. AC participated in the study to identify the interaction partners of AICD in cell lines and CSF. He also contributed in drafting the manuscript. SS contributed in drafting the manuscript. DM conceived of the studies, participated in their design and coordination and helped to draft the manuscript. All authors have read and approved the final manuscript.

\section{Acknowledgements}

Work in this area was conducted with joint collaboration of Saha Institute of Nuclear Physics, Kolkata and Nil Ratan Sircar Medical College and Hospital, Kolkata, India. The work was funded by Integrative Biology on Omics Platform (IBOP) project (Grant Number: 12-R\&D-SIN-5.04-0101) of Department of Atomic Energy (DAE), Govt. of India.

\section{Competing interests}

The authors declare that they have no competing interests. All authors have checked the manuscript and agree to its publication.

Received: 2 January 2016 Accepted: 18 April 2016

Published online: 05 May 2016 


\section{References}

1. Chevalier-Larsen E, Holzbaur EL. Axonal transport and neurodegenerative disease. Biochim Biophys Acta. 2006;1762(11-12):1094-108.

2. De Vos KJ, Grierson AJ, Ackerley S, Miller CC. Role of axonal transport in neurodegenerative diseases. Annu Rev Neurosci. 2008;31:151-73.

3. Abe N, Cavalli V. Nerve injury signaling. Curr Opin Neurobiol. 2008;18(3):276-83.

4. Rishal I, Fainzilber M. Retrograde signaling in axonal regeneration. Exp Neurol. 2010:223(1):5-10.

5. Sun F, Cavalli V. Neuroproteomics approaches to decipher neuronal regeneration and degeneration. Mol Cell Proteomics. 2010;9(5):963-75.

6. Pal R, Alves G, Larsen JP, Moller SG. New insight into neurodegeneration: the role of proteomics. Mol Neurobiol. 2014;49(3):1181-99.

7. Koyama A, Okereke OI, Yang T, Blacker D, Selkoe DJ, Grodstein F. Plasma amyloid-beta as a predictor of dementia and cognitive decline: a systematic review and meta-analysis. Arch Neurol. 2012;69(7):824-31.

8. Liao PC, Yu L, Kuo CC, Lin C, Kuo YM. Proteomics analysis of plasma for potential biomarkers in the diagnosis of Alzheimer's disease. Proteomics Clin Appl. 2007;1 (5):506-12.

9. Kiddle SJ, Sattlecker M, Proitsi P, Simmons A, Westman E, Bazenet C, Nelson SK, Williams S, Hodges A, Johnston C, et al. Candidate blood proteome markers of Alzheimer's disease onset and progression: a systematic review and replication study. J Alzheimers Dis. 2014;38(3):515-31.

10. Blennow K, Hampel H, Weiner M, Zetterberg H. Cerebrospinal fluid and plasma biomarkers in Alzheimer disease. Nat Rev Neurol. 2010;6(3):131-44

11. Sui X, Liu J, Yang X. Cerebrospinal fluid biomarkers of Alzheimer's disease. Neurosci Bull. 2014;30(2):233-42.

12. Ren RJ, Dammer EB, Wang G, Seyfried NT, Levey Al. Proteomics of protein post-translational modifications implicated in neurodegeneration. Transl Neurodegener. 2014;3(1):23.

13. Palmigiano A, Barone R, Sturiale L, Sanfilippo C, Bua RO, Romeo DA, Messina A, Capuana ML, Maci T, Le Pira F et al. CSF N-glycoproteomics for early diagnosis in Alzheimer's disease. J Proteomics. 2015;131:29-37.

14. Sihlbom C, Davidsson P, Sjogren M, Wahlund LO, Nilsson CL. Structural and quantitative comparison of cerebrospinal fluid glycoproteins in Alzheimer's disease patients and healthy individuals. Neurochem Res. 2008;33(7):1332-40

15. Zahid S, Khan R, Oellerich M, Ahmed N, Asif AR. Differential S-nitrosylation of proteins in Alzheimer's disease. Neuroscience. 2014;256:126-36.

16. Anderson KW, Turko IV. Histone post-translational modifications in frontal cortex from human donors with Alzheimer's disease. Clin Proteomics. 2015;12:26.

17. Dammer EB, Lee AK, Duong DM, Gearing M, Lah J, Levey Al, Seyfried NT. Quantitative phosphoproteomics of Alzheimer's disease reveals cross-talk between kinases and small heat shock proteins. Proteomics. 2015;15(2-3):508-19.

18. Di Domenico F, Sultana R, Barone E, Perluigi M, Cini C, Mancuso C, Cai J, Pierce WM, Butterfield DA. Quantitative proteomics analysis of phosphorylated proteins in the hippocampus of Alzheimer's disease subjects. J Proteomics. 2011;74(7):1091-103.

19. Triplett JC, Swomley AM, Cai J, Klein JB, Butterfield DA. Quantitative phosphoproteomic analyses of the inferior parietal lobule from three different pathological stages of Alzheimer's disease. J Alzheimers Dis. 2015:49(1):45-62

20. Swomley AM, Forster S, Keeney JT, Triplett J, Zhang Z, Sultana R, Butterfield DA. Abeta, oxidative stress in Alzheimer disease: evidence based on proteomics studies. Biochim Biophys Acta. 2014;1842(8):1248-57.

21. Butterfield DA, Swomley AM, Sultana R. Amyloid beta-peptide (1-42)-induced oxidative stress in Alzheimer disease: importance in disease pathogenesis and progression. Antioxid Redox Signal. 2013;19(8):823-35.

22. Swomley AM, Butterfield DA. Oxidative stress in Alzheimer disease and mild cognitive impairment: evidence from human data provided by redox proteomics. Arch Toxicol. 2015;89(10):1669-80.

23. Sultana R, Butterfield DA. Oxidative modification of brain proteins in Alzheimer's disease: perspective on future studies based on results of redox proteomics studies. J Alzheimers Dis. 2013;33(Suppl 1):S243-51.

24. Shen L, Chen C, Yang A, Chen Y, Liu Q, Ni J. Redox proteomics identification of specifically carbonylated proteins in the hippocampi of triple transgenic Alzheimer's disease mice at its earliest pathological stage. Journal of proteomics. 2015;123:101-13.

25. Drummond ES, Nayak S, Ueberheide B, Wisniewski T. Proteomic analysis of neurons microdissected from formalin-fixed, paraffin-embedded Alzheimer's disease brain tissue. Sci Rep. 2015;5:15456.

26. Chang RY, Etheridge N, Dodd PR, Nouwens AS. Targeted quantitative analysis of synaptic proteins in Alzheimer's disease brain. Neurochem Int. 2014;75:66-75.

27. Zhou J, Jones DR, Duong DM, Levey Al, Lah JJ, Peng J. Proteomic analysis of postsynaptic density in Alzheimer's disease. Clin Chim Acta. 2013:420:62-8.

28. Chang RY, Etheridge N, Nouwens AS, Dodd PR. SWATH analysis of the synaptic proteome in Alzheimer's disease. Neurochem Int. 2015;87:1-12

29. Patel S. Role of proteomics in biomarker discovery: prognosis and diagnosis of neuropsychiatric disorders. Adv Protein Chem Struct Biol. 2014;94(94):39-75.

30. Ahmed F, Ansari JA, Ansari ZE, Alam Q, Gan SH, Kamal MA, Ahmad E. A molecular bridge: connecting type 2 diabetes and Alzheimer's disease. CNS Neurol Disord Drug Targets. 2014;13(2):312-21.

31. Manral P, Sharma P, Hariprasad G, Chandralekha, Tripathi M, Srinivasan A. Can apolipoproteins and complement factors be biomarkers of Alzheimer's disease? Curr Alzheimer Res. 2012;9(8):935-43.

32. Muller T, Meyer HE, Egensperger R, Marcus K. The amyloid precursor protein intracellular domain (AICD) as modulator of gene expression, apoptosis, and cytoskeletal dynamics-relevance for Alzheimer's disease. Prog Neurobiol. 2008;85(4):393-406.

33. Nakayama K, Ohkawara T, Hiratochi M, Koh CS, Nagase H. The intracellular domain of amyloid precursor protein induces neuron-specific apoptosis. Neurosci Lett. 2008;444(2):127-31.

34. Ghosal K, Vogt DL, Liang M, Shen Y, Lamb BT, Pimplikar SW. Alzheimer's disease-like pathological features in transgenic mice expressing the APP intracellular domain. Proc Natl Acad Sci USA. 2009;106(43):18367-72.

35. Raychaudhuri M, Mukhopadhyay D. AICD and its adaptors - in search of new players. J Alzheimers Dis. 2007;11(3):343-58.

36. Kim HS, Kim EM, Lee JP, Park CH, Kim S, Seo JH, Chang KA, Yu E, Jeong SJ, Chong $\mathrm{YH}$, et al. C-terminal fragments of amyloid precursor protein exert neurotoxicity by inducing glycogen synthase kinase-3beta expression. FASEB J. 2003:17(13):1951-3.

37. Chakrabarti A, Mukhopadhyay D. Novel adaptors of amyloid precursor protein intracellular domain and their functional implications. Genomics Proteomics Bioinformatics. 2012;10(4):208-16.

38. Chakrabarti A, Chatterjee A, Sengupta MB, Chattopadhyay P, Mukhopadhyay D. Altered levels of amyloid precursor protein intracellular domain-interacting proteins in Alzheimer disease. Alzheimer Dis Assoc Disord. 2014;28(3):283-90.

39. Chakrabarti A, Roy K, Mukhopadhyay D. Differential expression of neuroblastoma cellular proteome due to AICD overexpression. J Alzheimers Dis. 2014;38(4):845-55.

40. Hagen EM, Rekand T, Gilhus NE, Gronning M. Traumatic spinal cord injuries-incidence, mechanisms and course. Tidsskr Nor Laegeforen. 2012;132(7):831-7.

41. Singh A, Tetreault L, Kalsi-Ryan S, Nouri A, Fehlings MG. Global prevalence and incidence of traumatic spinal cord injury. Clin Epidemiol. 2014;6:309-31.

42. Wyndaele M, Wyndaele JJ. Incidence, prevalence and epidemiology of spinal cord injury: what learns a worldwide literature survey? Spinal Cord. 2006;44(9):523-9.

43. Cripps RA, Lee BB, Wing P, Weerts E, Mackay J, Brown D. A global map for traumatic spinal cord injury epidemiology: towards a living data repository for injury prevention. Spinal Cord. 2011;49(4):493-501.

44. National Spinal Cord Injury Statistical Center. Spinal cord injury facts and figures at a glance. J Spinal Cord Med. 2013;36(5):568-9.

45. Karlsson AK. Autonomic dysfunction in spinal cord injury: clinical presentation of symptoms and signs. Prog Brain Res. 2006;152:1-8.

46. Dumont RJ, Okonkwo DO, Verma S, Hurlbert RJ, Boulos PT, Ellegala DB, Dumont AS. Acute spinal cord injury, part I: pathophysiologic mechanisms. Clin Neuropharmacol. 2001;24(5):254-64. 
47. Oyinbo CA. Secondary injury mechanisms in traumatic spinal cord injury: a nugget of this multiply cascade. Acta Neurobiol Exp. 2011;71(2):281-99.

48. Tanhoffer RA, Yamazaki RK, Nunes EA, Pchevozniki Al, Pchevozniki AM, Nogata C, Aikawa J, Bonatto SJ, Brito G, Lissa MD, et al. Glutamine concentration and immune response of spinal cord-injured rats. J Spinal Cord Med. 2007:30(2):140-6.

49. Massing MW, Robinson GA, Marx CE, Alzate O, Madison RD. Applications of proteomics to nerve regeneration research. In: Alzate $\mathrm{O}$, editor. Neuroproteomics. Chapter 15. Boca Raton (FL): CRC Press/Taylor \& Francis; 2010. http://www.ncbi.nlm.nih.gov/books/NBK56006/.

50. Ambron RT, Walters ET. Priming events and retrograde injury signals. A new perspective on the cellular and molecular biology of nerve regeneration. Mol Neurobiol. 1996;13(1):61-79.

51. Perlson E, Medzihradszky KF, Darula Z, Munno DW, Syed NI, Burlingame AL, Fainzilber M. Differential proteomics reveals multiple components in retrogradely transported axoplasm after nerve injury. Mol Cell Proteomics. 2004:3(5):510-20.

52. Perlson E, Hanz S, Ben-Yaakov K, Segal-Ruder Y, Seger R, Fainzilber M. Vimentin-dependent spatial translocation of an activated MAP kinase in injured nerve. Neuron. 2005;45(5):715-26.

53. Perlson E, Michaelevski I, Kowalsman N, Ben-Yaakov K, Shaked M, Seger R, Eisenstein M, Fainzilber M. Vimentin binding to phosphorylated Erk sterically hinders enzymatic dephosphorylation of the kinase. J Mol Biol. 2006;364(5):938-44

54. Kwon BK, Stammers AM, Belanger LM, Bernardo A, Chan D, Bishop CM, Slobogean GP, Zhang H, Umedaly H, Giffin M, et al. Cerebrospinal fluid inflammatory cytokines and biomarkers of injury severity in acute human spinal cord injury. J Neurotrauma. 2010;27(4):669-82.

55. Chen A, McEwen ML, Sun S, Ravikumar R, Springer JE. Proteomic and phosphoproteomic analyses of the soluble fraction following acute spinal cord contusion in rats. J Neurotrauma. 2010;27(1):263-74

56. Sengupta MB, Basu M, Iswarari S, Mukhopadhyay KK, Sardar KP, Acharyya B, Mohanty PK, Mukhopadhyay D. CSF proteomics of secondary phase spinal cord injury in human subjects: perturbed molecular pathways post injury. PLoS One. 2014; 9(10):e110885. doi:10.1371/journal. pone.0110885.

57. Lee JY, Kim BJ, Sim G, Kim GT, Kang D, Jung JH, Hwa JS, Kwak YJ, Choi YJ, Park YS, et al. Spinal cord injury markedly altered protein expression patterns in the affected rat urinary bladder during healing stages. J Korean Med Sci. 2011;26(6):814-23.

58. Yan X, Liu T, Yang S, Ding Q, Liu Y, Zhang X, Que H, Wei K, Luo Z, Liu S. Proteomic profiling of the insoluble pellets of the transected rat spinal cord. J Neurotrauma. 2009:26(2):179-93.

59. Wang CY, Chen JK, Wu YT, Tsai MJ, Shyue SK, Yang CS, Tzeng SF. ReduCtion in antioxidant enzyme expression and sustained inflammation enhance tissue damage in the subacute phase of spinal cord contusive injury. J Biomed Sci. 2011;18:13.

60. Tsai MC, Shen LF, Kuo HS, Cheng H, Chak KF. Involvement of acidic fibroblast growth factor in spinal cord injury repair processes revealed by a proteomics approach. Mol Cell Proteomics. 2008;7(9):1668-87.

61. Lubieniecka JM, Streijger F, Lee JH, Stoynov N, Liu J, Mottus R, Pfeifer T, Kwon BK, Coorssen JR, Foster LJ, et al. Biomarkers for severity of spinal cord injury in the cerebrospinal fluid of rats. PLoS One. 2011:6(4):e19247.

62. Afjehi-Sadat L, Brejnikow M, Kang SU, Vishwanath V, Walder N, Herkner K, Redl H, Lubec G. Differential protein levels and post-translational modifcations in spinal cord injury of the rat. J Proteome Res. 2010;9(3):1591-7.

63. Light M, Minor KH, DeWitt P, Jasper KH, Davies SJ. Multiplex array proteomics detects increased MMP-8 in CSF after spinal cord injury. J Neuroinflammation. 2012;9:122.

64. Zhu B, Li Y, Li M, Yang X, Qiu B, Gao Q, Liu J, Liu M. Dynamic proteome analysis of spinal cord injury after ischemia-reperfusion in rabbits by twodimensional difference gel electrophoresis. Spinal Cord. 2013;51(8):610-5.

65. Chen A, Sun S, Ravikumar R, Visavadiya NP, Springer JE. Differential proteomic analysis of acute contusive spinal cord injury in rats using iTRAQ reagent labeling and LC-MS/MS. Neurochem Res. 2013;38(11):2247-55.

66. Zhou Y, Xu L, Song X, Ding L, Chen J, Wang C, Gan Y, Zhu X, Yu Y, Liang $Q$. The potential role of heat shock proteins in acute spinal cord injury. Eur Spine J. 2014;23(7):1480-90.
67. Wang W, Yang T, Liu L, Pei F. Proteomics study on effect of basic fibroblast growth factor long circulation liposome on spinal cord traction injury in rats. Zhongguo Xiu Fu Chong Jian Wai Ke Za Zhi. 2014;28(11):1397-405.

68. Wadhwa G, Aikat R. Development, validity and reliability of the 'Sitting Balance Measure' (SBM) in spinal cord injury. Spinal Cord. 2015:54(4):319-23.

69. Mathur N, Jain S, Kumar N, Srivastava A, Purohit N, Patni A. Spinal cord injury: scenario in an Indian state. Spinal Cord. 2015;53(5):349-52.

70. Chhabra HS, Bhalla AM. Influence of socio-economic status on access to different components of SCI management across Indian population. Spinal Cord. 2015;53(11):816-20.

71. Magu S, Singh D, Yadav RK, Bala M. Evaluation of traumatic spine by magnetic resonance imaging and correlation with neurological recovery. Asian Spine J. 2015;9(5):748-56.

72. Singh R, Kumar RR, Setia N, Magu S. A prospective study of neurological outcome in relation to findings of imaging modalities in acute spinal cord injury. Asian J Neurosurg. 2015:10(3):181-9.

73. Gupta DK, Vaghani G, Siddiqui S, Sawhney C, Singh PK, Kumar A, Kale SS, Sharma BS. Early versus delayed decompression in acute subaxial cervical spinal cord injury: a prospective outcome study at a level I trauma center from India. Asian J Neurosurg. 2015;10(3):158-65.

74. Maynard FM Jr, Bracken MB, Creasey G, Ditunno JF Jr, Donovan WH, Ducker TB, Garber SL, Marino RJ, Stover SL, Tator CH, et al. International standards for neurological and functional classification of spinal cord injury. American Spinal Injury Association. Spinal Cord. 1997;35(5):266-74

75. Newman ME. Modularity and community structure in networks. Proc Natl Acad Sci USA. 2006;103(23):8577-82.

76. Lancichinetti A, Kivela M, Saramaki J, Fortunato S. Characterizing the community structure of complex networks. PLoS One. 2010;5(8):e11976.

77. Clauset A, Newman ME, Moore C. Finding community structure in very large networks. Phys Rev E Stat Nonlin Soft Matter Phys. 2004;70(6 Pt 2):066111.

78. da Huang W, Sherman BT, Lempicki RA. Bioinformatics enrichment tools: paths toward the comprehensive functional analysis of large gene lists. Nucleic Acids Res. 2009;37(1):1-13.

79. Tabas-Madrid D, Nogales-Cadenas R, Pascual-Montano A. GeneCodis3: a non-redundant and modular enrichment analysis tool for functional genomics. Nucleic Acids Res. 2012;40(Web Server issue):W478-83.

80. Jacob A, Matiello M, Wingerchuk DM, Lucchinetti CF, Pittock SJ, Weinshenker BG. Neuromyelitis optica: changing concepts. J Neuroimmunol. 2007:187(1-2):126-38.

81. Kim W, Kim SH, Kim HJ. New insights into neuromyelitis optica. J Clin Neurol. 2011;7(3):115-27.

82. Bergamaschi R, Tonietti S, Franciotta D, Candeloro E, Tavazzi E, Piccolo G, Romani A, Cosi V. Oligoclonal bands in Devic's neuromyelitis optica and multiple sclerosis: differences in repeated cerebrospinal fluid examinations. Mult Scler. 2004;10(1):2-4.

83. Mata S, Lolli F. Neuromyelitis optica: an update. J Neurol Sci. 2011;303(1-2):13-21.

84. Wingerchuk DM, Hogancamp WF, O'Brien PC, Weinshenker BG. The clinical course of neuromyelitis optica (Devic's syndrome). Neurology. 1999:53(5):1107-14.

85. Lennon VA, Wingerchuk DM, Kryzer TJ, Pittock SJ, Lucchinetti CF, Fujihara K, Nakashima I, Weinshenker BG. A serum autoantibody marker of neuromyelitis optica: distinction from multiple sclerosis. Lancet. 2004;364(9451):2106-12.

86. Wingerchuk DM, Lennon VA, Pittock SJ, Lucchinetti CF, Weinshenker BG. Revised diagnostic criteria for neuromyelitis optica. Neurology. 2006:66(10):1485-9.

87. Etemadifar M, Nasr Z, Khalili B, Taherioun M, Vosoughi R. Epidemiology of neuromyelitis optica in the world: a systematic review and metaanalysis. Mult Scler Int. 2015;2015:174720.

88. Mealy MA, Wingerchuk DM, Greenberg BM, Levy M. Epidemiology of neuromyelitis optica in the United States: a multicenter analysis. Arch Neurol. 2012;69(9):1176-80.

89. Rivera JF, Kurtzke JF, Booth VJ. Corona VTt: Characteristics of Devic's disease (neuromyelitis optica) in Mexico. J Neurol. 2008;255(5):710-5. 
90. Lana-Peixoto MA. Devic's neuromyelitis optica: a critical review. Arq Neuropsiquiatr. 2008;66(1):120-38.

91. Wingerchuk DM. Neuromyelitis optica: effect of gender. J Neurol Sci. 2009;286(1-2):18-23.

92. Cossburn M, Tackley G, Baker K, Ingram G, Burtonwood M, Malik G, Pickersgill T, te Water Naude J, Robertson N. The prevalence of neuromyelitis optica in South East Wales. Eur J Neurol. 2012;19(4):655-9.

93. Banwell B, Tenembaum S, Lennon VA, Ursell E, Kennedy J, Bar-Or A, Weinshenker BG, Lucchinetti CF, Pittock SJ. Neuromyelitis optica-lgG in childhood inflammatory demyelinating CNS disorders. Neurology. 2008;70(5):344-52.

94. Wingerchuk DM, Weinshenker BG. Neuromyelitis optica: clinical predictors of a relapsing course and survival. Neurology. 2003;60(5):848-53.

95. Staugaitis SM, Roberts JK, Sacco RL, Miller JR, Dwork AJ. Devic type multiple sclerosis in an 81 year old woman. J Neurol Neurosurg Psychiatry. 1998;64(3):417-8.

96. Wingerchuk DM, Weinshenker BG. Neuromyelitis optica. Curr Treat Options Neurol. 2005:7(3):173-82.

97. Singh V, Hintzen RQ, Luider TM, Stoop MP. Proteomics technologies for biomarker discovery in multiple sclerosis. J Neuroimmunol. 2012;248(1-2):40-7.

98. Yuan X, Desiderio DM. Proteomics analysis of human cerebrospinal fluid. J Chromatogr B Analyt Technol Biomed Life Sci. 2005;815(1-2):179-89.

99. Khwaja FW, Nolen JD, Mendrinos SE, Lewis MM, Olson JJ, Pohl J, Van Meir EG, Ritchie JC, Brat DJ. Proteomic analysis of cerebrospinal fluid discriminates malignant and nonmalignant disease of the central nervous system and identifies specific protein markers. Proteomics. 2006;6(23):6277-87.

100. Jiang S, Wu J, Yang Y, Liu J, Ding Y, Ding M. Proteomic analysis of the cerebrospinal fluid in multiple sclerosis and neuromyelitis optica patients. Mol Med Report. 2012;6(5):1081-6.

101. Przyjalkowski W, Lipowski D, Kolasa T, Issa E, Olejnik Z. Blood-cerebrospinal fluid barrier in purulent cerebrospinal meningitis. Neurol Neurochir Pol. 1996;30(1):39-48.

102. Bai S, Liu S, Guo X, Qin Z, Wang B, Li X, Qin Y, Liu YH. Proteome analysis of biomarkers in the cerebrospinal fluid of neuromyelitis optica patients. Mol Vis. 2009;15:1638-48.

103. Sjogren M, Blomberg M, Jonsson M, Wahlund LO, Edman A, Lind K, Rosengren L, Blennow K, Wallin A. Neurofilament protein in cerebrospinal fluid: a marker of white matter changes. J Neurosci Res. 2001:66(3):510-6.

104. Jiang SF, Lu QY, Hu S, Chen Y, Liu XL, Yang Y, Ding MP. Proteomics comparison of the sera from multiple sclerosis patients and neuromyelitis optica patients. Genet Mol Res. 2014;13(4):9292-9.

105. Nielsen HH, Beck HC, Kristensen LP, Burton M, Csepany T, Simo M, Dioszeghy P, Sejbaek T, Grebing M, Heegaard NH, et al. The urine proteome profile is different in neuromyelitis optica compared to multiple sclerosis: a clinical proteome study. PLoS One. 2015;10(10):e0139659.

\section{Submit your next manuscript to BioMed Central and we will help you at every step:}

- We accept pre-submission inquiries

- Our selector tool helps you to find the most relevant journal

- We provide round the clock customer support

- Convenient online submission

- Thorough peer review

- Inclusion in PubMed and all major indexing services

- Maximum visibility for your research

Submit your manuscript at www.biomedcentral.com/submit 